\title{
Cryptocurrencies as a Disruption? Empirical Findings on User Adoption and Future Potential of Bitcoin and Co.
}

\author{
Aaron W. Baur, Julian Bühler, Markus Bick, and Charlotte S. Bonorden \\ ESCP Europe Business School Berlin, Berlin, Germany \\ \{abaur, jbuehler, mbick\}@escpeurope.eu, \\ charlotte.bonorden@edu.escpeurope.eu
}

\begin{abstract}
In this paper, we examine cryptocurrencies as a potentially disruptive sort of payment method. Due to its relative importance, we focus in particular on Bitcoin. Through an inductive, exploratory interview approach with 13 individuals in three distinct groups, the determinants usability, usefulness, and subjective norm that could make Bitcoin a game-changer are explored. The results reveal that most stakeholders consider perceived ease of use still rather low, with perceived usefulness varying according to the user group. The notion of Bitcoin as having much future potential as a payment method is confirmed across all interviewees. Interestingly, the underlying concept of a blockchain is also seen as a potential revolutionary way to create a more just society based on open platforms and open data. However, the reasons of why Bitcoin is actually a disruption to existing solutions varies widely.
\end{abstract}

Keywords: electronic payment, Bitcoin, cryptocurrency, digital currency, e-commerce, technology adoption, TAM, blockchain

\section{Introduction}

The Internet and the massive growth of e-commerce have bred various new online payment and money transaction methods in the last several years. This is being spurred by a new hype in 'fin-tech' startups in the global technology hubs. Even though famous quotes like "banking is necessary, banks are not" made by former Wells Fargo CEO Richard Kovacevich [1] are already quite dated, technology finally seems ready to enable real innovations in this sector. A new generation of founders is motivated to revolutionize how the financial industry works, what society thinks about the concept of money, and how the future of monetary transactions will look.

As the number of alternative payment types has grown, traditional means of online payment, like credit cards, are on the downgrade as they are fighting with competition that offers higher user-friendliness, more security, and lower costs [2, 3]. As Koley [4] reports, even though the virtual duopoly of Visa and MasterCard is still experiencing healthy growth rates $(9.5 \%$ and $9.6 \%$, respectively) and remains the preferred method for (offline) point-of-sale (POS) transactions, firms like JCB and UnionPay outperform them by far (growing $20.7 \%$ and $44.8 \%$, respectively). This provides hints 
of altered consumer behavior including a perceived viable alternative to credit cards and a gradual change in the payment market [5]. PayPal, which was originally meant for facilitating eBay transactions, is now one of the major players in online payment [6]. Additionally, new firms that are home to completely different industries than banking, like Google and Apple, offer solutions that have already gained a remarkable level of user acceptance and dissemination among society and businesses alike [7, 8]. However, all of these solutions remain tied in one way or another to the user's regular bank account and a traditional notion of the concept money.

Another, potentially far more disruptive innovation in this field applies to cryptocurrencies [9]. Advocates of these new means of payment claim various advantages, like a fully decentralized, peer-to-peer transaction system, elimination of chargeback risks, lower associated transaction costs, increased level of security, greater ease of use, and full support for mobile devices $[10,11]$. Of the several hundred different cryptocurrencies, ${ }^{1}$ Bitcoin is the most well-known, most discussed, and most widely traded one with a market capitalization of more than three bn USD (see Figure 1 for the top ten cryptocurrencies as of May 15, 2015). Hence, in this paper we focus on Bitcoin and use 'Bitcoin' and 'cryptocurrency' somewhat interchangeably.

\begin{tabular}{|c|c|c|}
\hline Rank & Name & Market Cap \\
\hline 1 & B Bitcoin & $\$ 3,372,991,146$ \\
\hline 2 & - Ripple & $\$ 213,123,917$ \\
\hline 3 & (15) Litecoin & $\$ 56,741,480$ \\
\hline 4 & () Dash & $\$ 15,396,138$ \\
\hline 5 & f) Stellar & $\$ 13,645,326$ \\
\hline 6 & (1) Dogecoin & $\$ 11,934,891$ \\
\hline 7 & BitShares & $\$ 9,554,346$ \\
\hline 8 & S $\mathrm{Nxt}$ & $\$ 9,217,893$ \\
\hline 9 & (viv) BanxShares & $\$ 7,508,688$ \\
\hline 10 & D) Peercoin & $\$ 5,772,497$ \\
\hline
\end{tabular}

Fig. 1. Top ten cryptocurrencies and market cap in USD, as of May 15, 2015 2

The body of scientific research in the field of cryptocurrencies is still very manageable (see Related Work section below). One stream that especially lacks work is the question of user adoption and the relevant drivers of it (e.g., [12, 13]). Academic research has mostly neglected the user perspective, which connects the technological infrastructure with the established economies [12]. In particular, the decisive impact on society as a whole that users expect of these blockchain technologies has not been gathered. To the best of our knowledge, there has not been any empirical research applying detailed interviews to gain 'rich knowledge' about these kinds of questions. With this paper, we contribute to this under-researched turf by means of an exploratory, qualitative approach using 13 semi-structured interviews.

In particular, the study aims to examine the following research questions:

\footnotetext{
${ }^{1}$ The website https://coinmarketcap.com lists 560 as of May 15, 2015.

${ }^{2}$ Source: http://coinmarketcap.com/currencies/views/all/
} 
1. What are the perceived advantages and disadvantages of Bitcoin as compared to other forms of (electronic) payment?

2. What are the drivers and barriers Bitcoin users, merchants, and experts see in the adoption of Bitcoin?

3. How do users, merchants, and experts evaluate the future potential of Bitcoin as a serious means of currency, unit of account, asset, and disruption for society?

The remainder of this paper is structured as follows: After giving an overview of the applicable literature on cryptocurrencies and present payment options, the applied research methodology is presented. In the following part, the interview findings are discussed. The paper closes with a conclusion section and also discusses contributions, limitations, and future avenues to advance this research area.

The aim is to explore Bitcoin's main advantages and disadvantages compared to current payment types, to identify the drivers and barriers of Bitcoin's adoption, and to evaluate its future potential as seen by the three distinct groups of (pure) users, merchants, and experts.

\section{$2 \quad$ Related Work}

In order to find empirical works on Bitcoin adoption and usage, we conducted a thorough literature search following the frameworks of vom Brocke et al., Levy and Ellis, and Webster and Watson [14-16]. Search terms were 'Bitcoin', 'crypto AND currency[ies]', and 'cryptocurrency[-ies]'. As suggested by Chen et al. [17], we searched the databases Web of Science, EBSCO Business Source Complete, IEEE Xplore, ScienceDirect, and the ACM Digital Library. To be as exhaustive as possible, the important IS conferences ICIS, ECIS, HICSS, PACIS, and AMCIS were also explored with the identical keywords. As the 'mother paper' of Bitcoin by Satoshi Nakamoto (most likely a group pseudonym) was just released in 2008 [18], we did not limit the search timeframe. In fact, it was not until 2011 that research papers about cryptocurrencies were published in journals and from conferences. From 2013, larger peer-reviewed journals have been picking up the topic and have started to accept papers more frequently.

The results, combined with the work of Scott [19] and Böhme et al. [20], revealed four main streams of research in regard to Bitcoin, addressing three different layers:

- Technical: This stream includes technical details about the 'back-end' of cryptocurrency, like cryptography, mathematical models, and system design. It consists of two sub-streams: On the one hand, conceptual and prototyping work in regard to the protocol layer (e.g., [21-23]), and on the other, research concerning the network layer, i.e., mainly security-related works made up of experimental and quantitative research designs (e.g., [24-26]). 
The other three streams address the ecosystem layer:

- Economic: This body of research looks at cryptocurrency from an economist's perspective, and mainly includes traditional economic models, portfolio theory, incentive structures, and the like (e.g., [20, 27-31]).

- Regulatory: Here, researchers discuss legal, fiscal, tax, and regulatory issues of Bitcoin as a new form of currency (e.g., [10, 32-34]).

- Social Science: Along this road, this research is about sociology, trust, anthropology, ethics, and politics in regard to the new phenomenon of cryptocurrencies (e.g., [35-38]).

Surprisingly, the Social Science branch is the least developed, but probably the most relevant for Information Systems (IS) research. Hence, this paper focuses on this human-centered aspect of cryptocurrency.

\subsection{Traditional Digital Payment Solutions}

For a long time, credit cards have been the dominant means of payment on the Internet. Credit cards like Visa, MasterCard, American Express, and Discover still denote the highest volumes of all forms of payments. For instance, daily transaction volumes of Visa amount to almost 18 bn USD (Figure 2.). Due to certain drawbacks of credit cards to merchants and consumers - e.g., the possibility of chargebacks, high fees, and a significant fraud risk - a wide array of alternative means of online payment has developed. Important players include China Union Pay, PayPal, and increasingly Bitcoin, albeit with a huge gap when compared to their old-school credit card competitors.

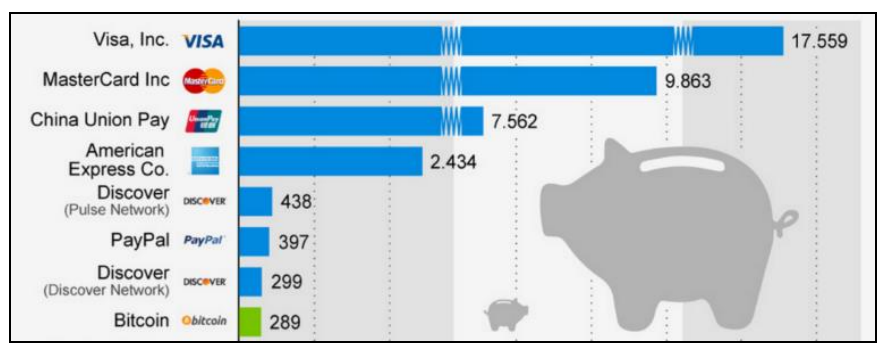

Fig. 2. Daily transaction volume in mn USD, as of the end of $2013^{3}$

New players from the 'fin-tech' startup realm enter the market and push the financial market to become more digital and more efficient, encouraging higher transaction volumes and enhancing security. Payment service providers advertise better security standards, a better ease of use, and lower fees. However, none of the current alternatives could so far solve the three inherent major flaws completely.

\footnotetext{
${ }^{3}$ Source: http://statista.com
} 
- Payments through alternative providers still run through customers' credit/debit cards or bank accounts, so transaction fees cannot be cut entirely, and the savings are sometimes even marginal. Furthermore, cross-border transactions still involve significant fees, regardless of whether the money is transferred directly via credit card or via a service like PayPal or Skrill.

- The risk of fraud is still present, as every time a customer purchases goods online, his or her personal data like name, address, and financial information are transferred over the Internet. This information therefore remains prone to identity theft, no matter whether it is stored only at one single point (PayPal) or at several.

- Usability or ease of use is still a major weakness, especially concerning older people who would like to purchase goods online.

These flaws and other ideas have led to a completely new approach to e-payment: cryptocurrencies.

\subsection{Overview of Cryptocurrency}

From a technical perspective, cryptocurrency can be defined as a "type of digital currency which relies on cryptography, usually alongside a proof-of-work scheme, in order to create and manage the currency. A decentralized network of peer-to-peer computer nodes working in sync creates and verifies transactions of transfer of said currency within the network" [39]. A more practical definition is given by Ametrano [40], stating that cryptocurrency "can be transferred instantly and securely between any two parties, using the Internet infrastructure and cryptographic security with no need for a trusted third party. Its value is not backed by any single government or organization." Furthermore, Wiatr [41] gives the definition that "a cryptocurrency is a modern digital medium of exchange. It is a new decentralized, limited and peer-topeer payment system. Most cryptocurrencies are created to introduce new units of currency, whose total amount is limited. All cryptocurrencies use cryptography to control the creation and transfer of money." Summarizing the above, we basically follow Spenkelink [42] and find four main characteristics of cryptocurrencies. First, cryptocurrency works through a decentralized network, meaning that it is free of any external regulations. Second, it has a strong $\mathrm{P} 2 \mathrm{P}$-approach. This guarantees the direct transaction of money between two parties, regardless of whether it is B2B, B2C, or $\mathrm{C} 2 \mathrm{C}$. Third, it uses the public Internet, which provides speed, efficiency, and resilience. Finally, cryptocurrency uses public-key cryptography to make money transactions as secure as possible.

After the introduction of Bitcoin as the first digital currency in 2009, the number of cryptocurrencies began to rise, and it quickly became a global phenomenon [43, 44]. Besides Bitcoin, there are hundreds of alternatives, each with different strengths. For example, Litecoin uses the scrypt encryption and claims to transact four times faster than Bitcoin, making it a viable alternative for high-speed applications like financial trading [20]. The so-called Altcoins can be regarded as 'forks' of either Bitcoin or Litecoin, since they are based on the same type of algorithms. Examples include Feathercoin, ChinaCoin, and Dogecoin [39]. 
Even though in theory Bitcoins can be mined, i.e., created by everyone, the system behind Bitcoin ensures certain characteristics that are important conditions for valid (fiat) currencies. First, scarcity: Bitcoins are limited to 21 million, keeping inflation low [45]. Second, security: Bitcoin follows the highest security standards using public and private keys [46]. After a person registers as a Bitcoin provider, he or she gets a digital wallet identification number (ID) that will be shown in public, once the person transfers Bitcoin. All past transactions are recorded in the blockchain. Third, simplicity: Transferring Bitcoins is easy, requiring a Bitcoin application or wallet on a mobile device and the required amount of Bitcoins, normally received through a Bitcoin exchange or an ATM. ${ }^{4}$ The transfer then only takes minutes, regardless of geographical distance.

\subsection{Value-Add and Risks of Cryptocurrencies}

Most authors support the argument that Bitcoin has a significant future and will become a larger threat for credit card companies [2, 47, 48], but for now the potential is estimated to be limited to only specific fields [13, 49]. Grinberg [11] underlines the fact that Bitcoin is likely to be the new, revolutionary payment method for micropayments, because those are hardly profitable when credit card fees are applied to such small notional amounts. Böhme et al. [20] argue that it is becoming less certain whether the design of Bitcoin meets the requirements to replace credit card payments for the everyday consumer, particularly with regard to security standards. Furthermore, they illustrate the fact that there are numerous competing virtual currencies, for instance Litecoin that accelerates payment confirmations, or 'NXT' that reduces computational requirements. To become an essential part of the customer's daily life, Bitcoin first needs to achieve the overall reliance in value offer and user adoption.

Spenkelink [42] follows a broader perspective by concluding that the future of cryptocurrencies is very unclear in general and one can only speculate about its development. He further claims that many different usage scenarios and different stakeholder needs prevail, which makes the estimation of Bitcoin's mass adoption even harder. Descôteaux [50] holds the opinion that for the future development of Bitcoin, an appropriate legal and regulatory framework is extremely important in order to overcome the existing risks and threats slowing down the adoption of cryptocurrency. The literature also discusses the drawbacks and disadvantages of Bitcoin, such as the possibility of money laundering [51-54], trade in various illegal goods [55, 56], potential financing of terrorism [51, 57], Bitcoin loss or theft $[21,58]$, and tax evasion or enormous volatility $[27,43,59]$. These aspects were also mentioned by our interview partners.

\footnotetext{
${ }^{4}$ The website http://coinatmradar.com/ lists 389 ATMs globally as of May 15, 2015.
} 


\section{Research Methodology}

As described above, only limited research on Bitcoin's advantages, disadvantages, disruptive potentials, and adoption drivers exists. Therefore, we approached the research by following an entirely open, inductive, exploratory research design [60, 61]. Accordingly, an interview guideline was designed based on the literature review, but also including very open questions to motivate interviewees to come up with their own ideas, thoughts, anecdotes, and reasoning. To get insights into how different groups see and experience Bitcoin, the guideline was used to conduct semi-structured interviews in November and December 2014. To gain maximum diversity and coverage, 13 interviews with individuals from three distinct groups were used as a sample $[62,63]$. These are end-consumers, e-commerce merchants, and employees of Bitcoin exchanges with differing levels of experience with Bitcoin (see Table 1 for the sample description). The selection of the interview partners was based on a purposive sampling strategy [64]. This ensured the inclusion of a wide array of aspects of the evidence gathered from informants $[65,66]$. The interviews were recorded and subsequently transcribed [66]. They lasted between 34 and 56 minutes.

Table 1. Sample description

\begin{tabular}{|c|c|c|c|c|}
\hline Individual & Group & Occupation & $\begin{array}{c}\text { Bitcoin } \\
\text { Experience }\end{array}$ & $\begin{array}{l}\text { Means of } \\
\text { Interview }\end{array}$ \\
\hline C1 & \multirow{5}{*}{ Consumer } & Student & none & Face-to-Face \\
\hline $\mathrm{C2}$ & & Entrepreneur & medium & Face-to-Face \\
\hline $\mathrm{C3}$ & & Entrepreneur & extensive & Skype \\
\hline $\mathrm{C4}$ & & Scientist & none & Face-to-Face \\
\hline $\mathbf{C 5}$ & & Architect & none & Face-to-Face \\
\hline M1 & \multirow{4}{*}{$\begin{array}{l}\text { Merchant } \\
\text { (E- } \\
\text { Commerce) }\end{array}$} & Innovation Manager, Retail Industry & extensive & Skype \\
\hline M2 & & CEO, Wholesale Industry & none & Face-to-Face \\
\hline M3 & & Head of Digital, Media Industry & little & Face-to-Face \\
\hline M4 & & Market Researcher, Retail Industry & none & Skype \\
\hline B1 & \multirow{4}{*}{$\begin{array}{l}\text { Bitcoin } \\
\text { Exchange }\end{array}$} & CEO & extensive & Skype \\
\hline B2 & & СТO & extensive & Skype \\
\hline B3 & & Senior Marketer & medium & Face-to-Face \\
\hline B4 & & Accountant & medium & Face-to-Face \\
\hline
\end{tabular}

Interview transcripts were analyzed using the open-coding technique [67]. Relevant passages were identified and axial coding was subsequently used to refine the categories. The analysis was diligently carried out to fulfill the common requirements for qualitative research (e.g., [68-70]). The interpretation process was rule-driven and documented ("procedural validity"; [70]) In addition, we triangulated the data [70] by interviewing people with different perspectives on and knowledge about the phenomenon (i.e., three distinct user groups). Therefore, the results can be assumed to be reliable [71]. 


\section{$4 \quad$ Analysis and Results}

While analyzing the interview transcripts in order to find answers to the research questions, we decided to apply the established constructs perceived ease of use and perceived usefulness of the Technology Acceptance Model TAM [72, 73] and subjective norm of its successor, TAM2 [74, 75], as they work well as ordering categories. Another one, future potential, emerged out of the data. Table 2 summarizes the findings, which are organized around the four research constructs and the case codes. We have included original quotes, which is the 'beauty of qualitative research' [76] and more often than not provide the deepest insight into the matter. In the following paragraphs, we discuss the condensed quintessence of our findings.

Table 2. Findings and case coding

\begin{tabular}{|c|c|c|c|}
\hline 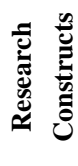 & Codes & $\begin{array}{l}\text { Opinions of Individuals } \\
\text { C = Consumer } \\
\text { M = Merchant } \\
\text { B = Bitcoin Exchange }\end{array}$ & Exemplifying Quotes \\
\hline \multirow[b]{5}{*}{ 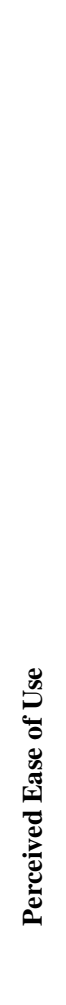 } & $\begin{array}{l}\text { Mobile } \\
\text { Wallets }\end{array}$ & $\begin{array}{l}\text { useful, but cumbersome (C1/ } \\
\text { 2/3); needs more development } \\
\text { and refinement }(\mathrm{C} 2) \text {; Bitcoin } \\
\text { best use case for wallets (B3) }\end{array}$ & $\begin{array}{l}\text { C2: "Google Wallet was really complicated and not } \\
\text { easy to use" } \\
\text { C5: "I have not yet dared to install some kind of } \\
\text { Wallet" }\end{array}$ \\
\hline & $\begin{array}{l}\text { Usage / } \\
\text { Implementa- } \\
\text { tion Process }\end{array}$ & $\begin{array}{l}\text { easy and self-explanatory }(\mathrm{C} 2) ; \\
\text { potentially easy }(\mathrm{C} 1 / \mathrm{C} 4 / \mathrm{M} 2) ; \\
\text { easy and fast, hard at POS } \\
(\mathrm{M} 1 / 3) \text {; easy, but not easy } \\
\text { enough for mainstream (B1/2/3) }\end{array}$ & $\begin{array}{l}\text { C1: "sounds pretty easy" } \\
\text { B1: "the general mainstream user has no clue about } \\
\text { Bitcoin" }\end{array}$ \\
\hline & $\begin{array}{l}\text { Technical } \\
\text { Understand- } \\
\text { ing (Expla- } \\
\text { nation) }\end{array}$ & $\begin{array}{l}\text { easy handling }(\mathrm{C} 2) \text {; merchants } \\
\text { also need training (B2); easy, } \\
\text { but concept and idea not yet } \\
\text { understood by society (B1/4) }\end{array}$ & M1: "not a technical, but a real societal challenge" \\
\hline & $\begin{array}{l}\text { Capability } \\
\text { (Educa- } \\
\text { tion/Age) }\end{array}$ & $\begin{array}{l}\text { some learning necessary }(\mathrm{C} 3) \\
\text { only accepted by generation } \\
\mathrm{Y} / \mathrm{Z}(\mathrm{B} 3 / 4)\end{array}$ & $\begin{array}{l}\text { C3: "you have to learn how to use it" } \\
\text { C1: "certainly, the under } 40 \text { crowd is far more } \\
\text { likely to embrace it, if it is convenient in the end" }\end{array}$ \\
\hline & $\begin{array}{l}\text { Perceived } \\
\text { Risks }\end{array}$ & $\begin{array}{l}\text { volatility (M1/2); advances in } \\
\text { technology and usability of } \\
\text { other mobile payments (B1); } \\
\text { security and storage (B2); use } \\
\text { as speculative trading device } \\
\text { (B1/2/3) }\end{array}$ & $\begin{array}{l}\text { B3: "the volatility of Bitcoin and the frictions of } \\
\text { moving money in and out of Bitcoin are a limiting } \\
\text { factor in its adoption" } \\
\text { B2: "Bitcoin also comes with the burden of keeping } \\
\text { it secure and accessible at the same time. No really } \\
\text { good solution exists yet that solves both problems } \\
\text { satisfactorily" }\end{array}$ \\
\hline
\end{tabular}




\begin{tabular}{|c|c|c|c|}
\hline & Convenience & $\begin{array}{l}\text { cuts out annoyance of searching } \\
\text { for cash at POS }(\mathrm{C} 1) \text {; Bitcoin } \\
\text { more convenient than rest } \\
(\mathrm{C} 2 / 3) \text {; with } \mathrm{QR} \text { code very } \\
\text { convenient }(\mathrm{B} 1 / 3)\end{array}$ & $\begin{array}{l}\text { M1: "convenient mobile payments arose at the } \\
\text { expense of security standards" } \\
\text { B1: "paying with Bitcoin is both convenient and } \\
\text { secure. We just need to scan a QR code in these } \\
\text { days and our payments are transferred successfully. } \\
\text { Anywhere, anytime" } \\
\text { B2: "just scan the QR code, done!" }\end{array}$ \\
\hline \multirow{5}{*}{ 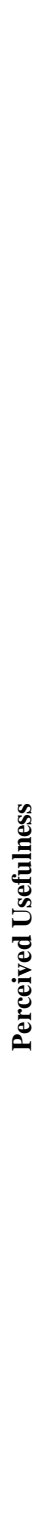 } & Anonymity & $\begin{array}{l}\text { big problem with CCs, Bitcoin } \\
\text { may be solution }(\mathrm{C} 1 / 2 / 3) \text {; } \\
\text { anonymity not an issue for } \\
\text { consumers, only important for } \\
\text { special target industries } \\
(\mathrm{M} 1 / 2 / 3, \mathrm{~B} 1 / 2 / 3 / 4)\end{array}$ & $\begin{array}{l}\text { C2: "people are more and more paranoid about } \\
\text { their privacy" } \\
\text { M1: "maybe relevant in gambling and sex busi- } \\
\text { ness" } \\
\text { M2: "higher anonymity will not increase payment } \\
\text { share of Bitcoin" }\end{array}$ \\
\hline & $\begin{array}{l}\text { Security / } \\
\text { Fraud }\end{array}$ & $\begin{array}{l}\text { involved in CC fraud }(\mathrm{C} 1) \text {, high } \\
\text { perceived level of security with } \\
\text { Bitcoin }(\mathrm{C} 1) ; 100 \% \text { security not } \\
\text { possible (all); fraud of CCs not } \\
\text { main argument (M1/2/3); secu- } \\
\text { rity a very strong Bitcoin bonus } \\
(\mathrm{B} 1 / 2 / 3)\end{array}$ & $\begin{array}{l}\text { C1: "American CCs are not as secure as European } \\
\text { ones that have chips in them, we have worse tech- } \\
\text { nology than Mongolia" } \\
\text { M1: "CC fraud covered by insurance" } \\
\text { M2: "Bitcoin accounts can be hacked as well and } \\
\text { used for transactions, hence fraud risk still exists" } \\
\text { B2: "blockchain technology serves as a trust anchor } \\
\text { for both parts of a trade" }\end{array}$ \\
\hline & $\begin{array}{l}\text { Transaction } \\
\text { Fees }\end{array}$ & $\begin{array}{l}\text { alternatives to CC highly need- } \\
\text { ed (C2); lower fees most per- } \\
\text { suasive argument for Bitcoin } \\
\text { (C1), wiring fees exorbitant } \\
\text { (C1); payout in local currency } \\
\text { will have high fees (M1); low } \\
\text { fees essential (M1/2/3); esp. } \\
\text { relevant to merchants (B1/2/3) }\end{array}$ & $\begin{array}{l}\text { C2: "airlines ripping people off when paying with } \\
\text { CC, very frustrating" } \\
\text { M1/2/3: "most promising argument for Bitcoin" } \\
\text { M3: "interesting for micropayments" } \\
\text { B1: "transaction costs have 'skyrocketed' in these } \\
\text { days and hence leave merchants from certain indus- } \\
\text { tries at a competitive disadvantage" }\end{array}$ \\
\hline & $\begin{array}{l}\text { Instant } \\
\text { Transactions }\end{array}$ & $\begin{array}{l}\text { more relevant to merchants } \\
(\mathrm{C} 1 / 2 / 3) \text {; instant transaction } \\
\text { very helpful }(\mathrm{M} 3 / 4) \text {; time and } \\
\text { no chargebacks strong argu- } \\
\text { ments pro Bitcoin }(\mathrm{B} 1 / 2 / 3)\end{array}$ & $\begin{array}{l}\text { M2: "receiving payout faster from customers to us } \\
\text { has its benefits and we would prefer it" } \\
\text { M3: "time is money, so great" } \\
\text { B1: "for merchants, Bitcoin displays a direct money } \\
\text { inflow of their revenues, whereas with CC payment } \\
\text { they need to wait for around a week to receive their } \\
\text { payments" }\end{array}$ \\
\hline & \begin{tabular}{|l} 
Global \\
Reach \& \\
Cross- \\
Border
\end{tabular} & $\begin{array}{l}\text { great not to search for ATM } \\
\text { abroad }(\mathrm{C} 1 / 3) \text {; Bitcoin attrac- } \\
\text { tive for remittance }(\mathrm{C} 3) \text {; inter- } \\
\text { national speed and simplicity } \\
\text { very persuasive }(\mathrm{B} 1 / 2 / 3)\end{array}$ & $\begin{array}{l}\text { B1: "SEPA has failed, a technology based system } \\
\text { like Bitcoin needed to increase speed and decrease } \\
\text { fees at the same time" } \\
\text { B2: "transfer money everywhere in the world at } \\
\text { velocity of sound. Payment providers like Western } \\
\text { Union have made that possible too, however at high } \\
\text { costs" }\end{array}$ \\
\hline
\end{tabular}




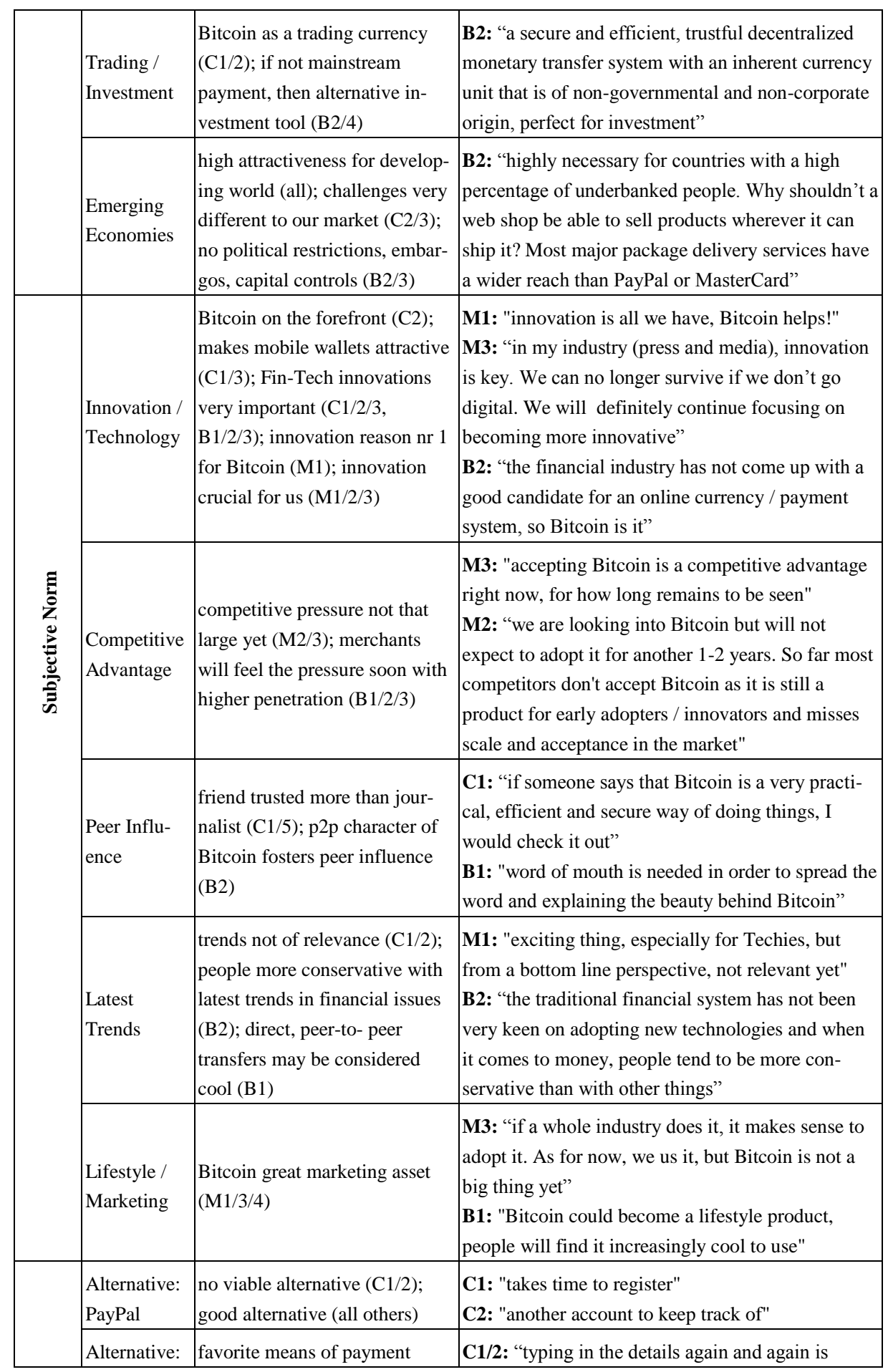




\begin{tabular}{|c|c|c|c|}
\hline \multirow{5}{*}{ 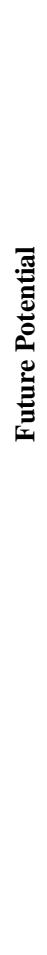 } & $\begin{array}{l}\text { Credit Card } \\
(\mathrm{CC})\end{array}$ & $\begin{array}{l}(\mathrm{C} 1 / 2) ; \text { insecure }(\mathrm{B} 1 / 2 / 3) ; \mathrm{OK} \\
(\mathrm{M} 1 / 2 / 3)\end{array}$ & $\begin{array}{l}\text { annoying" } \\
\text { M1: "used by majority of costumers" }\end{array}$ \\
\hline & $\begin{array}{l}\text { Alternative: } \\
\text { Others }\end{array}$ & $\begin{array}{l}\text { bank transfer / wire (all); Mas- } \\
\text { ter-pass / Sofortueberweisung } \\
\text { (all but } \mathrm{C} 1 / 2 / 3 \text { ) }\end{array}$ & $\begin{array}{l}\text { B3: "other alternatives will of course remain, but } \\
\text { become less and less important" }\end{array}$ \\
\hline & $\begin{array}{l}\text { Current } \\
\text { Subjective } \\
\text { Market } \\
\text { Penetration }\end{array}$ & $\begin{array}{l}\text { not clear who accepts Bitcoins } \\
\text { currently }(\mathrm{C} 1 / 2 / 3) \text {; still a niche } \\
\text { form of payment, low demand } \\
(\mathrm{M} 1 / 3) \text {; not really accepted } \\
(\mathrm{M} 2) \text {; customer demand drives } \\
\text { penetration }(\mathrm{B} 1 / 3 / 4)\end{array}$ & $\begin{array}{l}\text { C2: "recognizing more 'Pay with Bitcoin'-buttons } \\
\text { on official websites people would boost credibility" } \\
\text { B3: "current lack of easy-to-use and secure solu- } \\
\text { tions for storing and using Bitcoin without third- } \\
\text { party services do not make Bitcoin's advantages } \\
\text { apparent to new users" }\end{array}$ \\
\hline & $\begin{array}{l}\text { Subjective } \\
\text { Future } \\
\text { Market } \\
\text { Potential }\end{array}$ & $\begin{array}{l}\text { payout in local currency will } \\
\text { boost acceptance (M1/2); more } \\
\text { and more solutions pave way } \\
\text { for great potential (B2) }\end{array}$ & $\begin{array}{l}\text { C2: "will be the future", "easiest, most secure and } \\
\text { fastest way of payment" } \\
\text { M1: "will become a big thing in the future" } \\
\text { M2/3: "will be big, but never replace CCs" } \\
\text { B3: "Bitcoin is a very promising candidate for the } \\
\text { currency of the internet" }\end{array}$ \\
\hline & $\begin{array}{l}\text { Time Until } \\
\text { Widespread } \\
\text { Adoption }\end{array}$ & $\begin{array}{l}\text { quick adoption (C3); very } \\
\text { difficult to guess (all but C3); } \\
\text { probably very different speed in } \\
\text { different regions of world } \\
(\mathrm{M} 1 / 2, \mathrm{~B} 1 / 2 / 3)\end{array}$ & $\begin{array}{l}\text { M1: "in IT stuff, I stopped giving prognoses" } \\
\text { B1: "hard to tell, maybe } 3 \text { to } 5 \text { years, also depend- } \\
\text { ing on regulation/taxation/legislation" }\end{array}$ \\
\hline
\end{tabular}

\subsection{Perceived Ease of Use}

Consumers found mobile wallets and Bitcoin in general difficult to use, therefore requiring some training, although one interviewee regarded Bitcoin as easy and selfexplanatory. As buying, selling, or sending Bitcoin is very similar to using a Google Wallet, it is possible that more consumers will come across technical difficulties when using Bitcoin for the first time. They agreed that especially the younger generation should manage to handle Bitcoin and related software/apps, however. These findings are similar to those of Spenkelink [42]. Risks were not mentioned, but instead consumers focused on convenience, especially at offline stores (POS).

One merchant complained about the implementation process at POS and stressed that it's not a technical, but rather a societal challenge to switch to Bitcoin. Implementation in online shops was seen as fast and easy, and similar to other payment options. Most saw volatility as the main threat and agreed that current mobile payment solutions are convenient, but insecure; maybe Bitcoin can be a remedy here.

The representatives of Bitcoin exchanges saw Bitcoin as the best use case for mobile wallets. Even though they judged usage and implementation as easy, they still found it not easy enough. In fact, the whole cryptographic system behind Bitcoin was deemed just too complex to be understood by users and merchants, and it discouraged them from giving Bitcoin a try. However, their own companies and the majority of other exchanges already focus on emphasizing the easy set-up, integration, and usage 
of Bitcoin. This has been confirmed by a check on the landing pages of Bitpay, Cubits, Coinbase, and Safello. ${ }^{5}$ Here, tutorials, videos, and other training and marketing activities help users get started.

\subsection{Perceived Usefulness}

For consumers, anonymity and security rank very high. They feel threatened by credit card fraud and the old technology used, and consumers hope Bitcoin can be a remedy here. Due to high transaction fees of credit cards and especially money wiring (fees here seen as exorbitant), the lower costs are seen as the major argument for using Bitcoin. The instantaneous character of transactions was seen most relevant to merchants. The fact of doing away with ATM searches abroad once Bitcoin is also widely accepted at POS, and the possibility of doing remittances as well as using Bitcoin as an investment vehicle were all seen as very positive. Finally, Bitcoin was found especially suitable for emerging economies, as they face very different challenges (e.g., lack of availability of traditional banking services).

Merchants had a quite different view on anonymity and fraud: Anonymity was only crucial for special target groups, e.g., in online gambling or the sex business, not for mainstream costumers, thus stating the opposite of Pagliery [57]. The security of Bitcoin was also not necessarily seen as higher than that of credit cards, as Bitcoin accounts can also be hacked, which has happened before. Low transaction fees were the single most important argument for merchants, also in regard to micropayments. Having the payout of orders immediately on their accounts was also seen as very advantageous, as they are well aware that time is money.

Bitcoin exchange staff is more convinced about Bitcoin's usefulness regarding the elimination of fraud. All experts believe that security will become an increasing problem in the near future, which is why more secure payment solutions are necessary, and this is a big benefit of Bitcoin. In terms of anonymity, the necessity of finding ways to get rid of skyrocketing transaction fees, and the beneficial effect of instant transactions, the experts strongly agreed with the merchants. In terms of global and cross-border reach, the managers quoted pure speed and simplicity as persuasive arguments in favor of Bitcoin. Whereas one interviewee judged SEPA as failed, another mentioned Western Union as working, but at very high costs. Bitcoin as investment was regarded as ideal, as there is no government or corporate involvement. This is in strong opposition to the findings of Baek and Elbeck [27] and Garcia et al. [77], who see Bitcoin as far too speculative to be used by a non-professional investor. Lastly, emerging economies were mentioned as a suitable target market, since online shops often times can ship to remote locations, but cannot receive funds from there due to capital market restraints.

\footnotetext{
${ }^{5}$ https://bitpay.com; https://cubits.com; https://www.coinbase.com; https://safello.com
} 


\subsection{Subjective Norm}

In terms of innovation and technology, consumers rated Bitcoin to be very innovative, and it helps making mobile wallets attractive. In terms of peer influence, the interviewees so far unfamiliar with the (Bitcoin) process validated that they would give it a try upon recommendation of a friend. Two consumers denied that they give any relevance to current trends or lifestyle issues, i.e., Bitcoin plays no role here.

Merchants focused on the huge importance of innovation for their business, making this category the most decisive factor to offer Bitcoin payments. However, competitive pressure itself is currently still manageable, with one merchant confirming that they will look into it, but will probably not introduce it for another 1-2 years. One merchant claims Bitcoin to be a competitive advantage. In terms of trends, one merchant mentioned that it is a cool thing, especially for early-adopters/techies, but has no effect on revenue or profit, i.e., the bottom line. This statement basically confirms the research of Kostakis and Giotitsas [78]. The merchant also claims it to be somewhat a marketing tool, a thing to arouse interest and stand out from the crowd.

As the last group, Bitcoin exchange executives also stress fin-tech innovations as the key driver for competitiveness, ${ }^{6}$ making Bitcoin an important part of it. From their point of view, merchants should be preparing themselves, as competitive pressures to offer it as a payment solution will rise soon, triggered through increased word-ofmouth between users. Whether Bitcoin can be considered a 'cool trend', there are two different opinions: One manager confirms this, insisting that Bitcoin could become a lifestyle product, but another reminds us that when it comes to money issues, people are by far more conservative when compared to other areas of life.

\subsection{Future Potential}

The customers' overall opinion about Bitcoin is very positive; they perceive it as very promising. Nevertheless, credit cards, PayPal, and some other payment services are still and will for some time in the future be the most popular online payment method. Customers are aware of the benefits offered by Bitcoin and alternative means of payments in general, but experience a certain level of effort, through a cumbersome registration and administration effort. Issues with credit cards, e.g., manually typing in the card number and security code, seem to be tolerated until better solutions are developed and more transparency is created as to which shops actually accept Bitcoin.

Merchants strongly support cryptocurrency. Regardless of all arguments and restrictions discussed above, from a business perspective, Bitcoin seems to provoke large interest, and is seen as the future (therefore in line with Van Alstyne [33]). Hence, already two of the four interviewees accept Bitcoin. Nevertheless, the current customer demand is very low, so Bitcoin is still a pure niche product and will take time to develop.

As expected, the managers of Bitcoin exchanges have a very optimistic and positive view of Bitcoin's potential. However, the lack of secure storage and usage solu-

\footnotetext{
${ }^{6}$ European Commission: http://europa.eu/rapid/press-release_MEMO-13-719_en.htm
} 
tions hinders market penetration. A widespread initiative to push Bitcoin would be welcomed, and the type and extent of regulation will be decisive for its market penetration.

The high importance of educating people and businesses about the actual purpose and functioning of Bitcoin can be regarded as the unifying factor of all groups (in line with Papilloud and Haesler [79]). All interviewees also agreed that the actual timing of widespread adoption cannot be judged at all.

Interestingly, interviewees of all groups also mentioned the underlying blockchain as an idea and technology that could have a far-reaching, disruptive potential outside of the payment area. Applications as diverse as document version control, proof of whether a person's vote has been counted or clear identification for e-government and open data solutions were addressed.

\section{Conclusion}

\subsection{Contributions}

With this paper, we have contributed to answering several research questions relating to Bitcoin's relative advantages and disadvantages, the drivers and barriers of adoption, and the perceived future potentials from user and professional perspectives.

First, perceived ease of use among stakeholders is still considered rather low. Issues of usability of mobile wallets, implementation, storage, and transfer as well as offering user training are not solved satisfactorily yet. Risks like volatility, security, and accessibility remain. However, people who are using it confirm its high level of convenience. In total, some homework needs to be done here.

Second, perceived usefulness is confirmed for the main part, albeit not yet for the majority of online shoppers. Low transaction fees are central and pivotal to all interviewed individuals. A smaller influence is given to a somewhat higher anonymity and lower risk of fraud as well as faster claim of payments for merchants. Potential international reach and acceptance were also convincing. Bitcoin as a new investment class is controversial, but the high added value for less-developed countries is not.

Third, subjective norm is somewhat split. To use Bitcoin in innovation and in creating competitive advantage is for all groups of high importance. Peer-influence, the fact of being trendy or not, as well as lifestyle issues have less influence on the subjective norm of using Bitcoin.

Fourth, future potential was questioned by comparing it with alternatives. All of them are deemed important, but with a diminishing degree. Current market penetration is judged as very low, recognizing Bitcoin as a niche phenomenon. Subjective future potential is quite the opposite, with all groups assigning a boost in penetration and eventually becoming 'a big thing'. The actual timing of this boost was, however, not answered by anyone.

Fifth, this piece of research has found some evidence that Bitcoin, due to its completely new way of working without a central institution overseeing it, is about to become a serious new player in the online payment market. However, society and businesses are still far from embracing Bitcoin in their daily lives, making educating 
people about Bitcoin's advantages and use necessary. But Bitcoin's conditions seem good to become fully accepted and trusted by first addressing certain industries and later convincing the masses. One step in that direction may be seen in the latest techgiant Microsoft accepting Bitcoin for Apps, Windows licenses, Windows Phone, and Xbox in December 2014. ${ }^{7}$ Hence, policy-makers and merchants should be prepared.

Finally, the interviews brought additional areas of use of the blockchain scheme to the surface. The possibility to issue unique identifiers to things and people alike opens up immense opportunities in the future.

From a theoretical point of view, we help to expand the body of knowledge about users' acceptance, views, opinions, and feelings about cryptocurrencies - a very new social phenomenon. Additionally, online shops, policy-makers, and regulators should be alarmed that Bitcoin is indeed not just a crazy idea from some IT nerds, but a possible game changer for the future. They should take adequate measures to handle it.

\subsection{Limitations and Future Research}

Our paper suffers from some limitations. First, only 13 individuals were interviewed, which makes generalizations difficult, as is the case with most inductive, qualitative research. Based on these interview findings, as a follow-up, hypotheses could be formulated that are then tested in a large-scale quantitative survey in a deductive research setting. These survey results would then make generalizations possible. Second, there may be a bias that almost one-third of the interviewees work for Bitcoin exchanges and hence have an apparent interest in seeing cryptocurrencies as too positive. However, very new and potentially disruptive innovations demand to include the voice of professionals, who can judge the whole scope of the research object [65].

Overall, the paper lays a first foundation to spark future research avenues. Comparing developments in different parts of the world could debunk differences due to riskaversion (e.g., very high in Germany), methods of payment (e.g., widespread credit card use in the US), or technical availability (e.g., lack of traditional banking infrastructure in developing countries). Lastly, including the opinions of people from regulatory and administrative authorities could help in getting the complete picture of cryptocurrencies. And lastly, focusing more on the non-payment aspects of the blockchain technology to revolutionize society in the future may yield great additions to the body of knowledge in the social sciences.

These are just a few ideas contributing to the massive research effort that is still needed to completely understand the emergent and possibly disruptive nature of cryptocurrencies, and to see whether the blockchain can also contribute to a more just society, based on open platforms and open data with access for everyone.

\footnotetext{
7 http://blogs.microsoft.com/firehose/2014/12/11/now-you-can-exchange-bitcoins-to-buy-appsgames-and-more-for-windows-windows-phone-and-xbox
} 


\section{References}

1. Foster, G., Gupta, M., Palmer, R.: Business-to-Business Electronic Commerce. Cases in Strategic-Systems Auditing (1999)

2. Bourgeois, R.: Impact of PayPal, Google, Amazon \& Emerging Payment Providers on Visa, MasterCard \& Payment Industry. The Long-View: 2010 Edition U.S. Perspectives. Bernstein Global Wealth Management, 195-206 (2010)

3. Olsen, Ø.: Annual Report on Payment Systems 2012 (2013)

4. Koley, T.: End of Duopoly in Credit Card Payment Scheme Industry. Journal of Economics and Finance 4, 67-76 (2014)

5. Gonggrijp, S., Geerling, M., Mallekoote, P.: Successful introduction of new payment methods through 'co-opetition. Journal of Payments Strategy \& Systems 7, 136-149 (2013)

6. Conrad, L.: En Garde! Banks and PayPal Will Clash. U.S. Banker 117, 102 (2007)

7. Pogue, D.: The Future Is Plastic. Scientific American 312, 35 (2015)

8. Dempsey, P.: Is it time to take a reality check on the mobile payments market. Engineering \& Technology 9, 20 (2014)

9. Cusumano, M.A.: The Bitcoin ecosystem. Communications of the ACM 57, 2224 (2014)

10. Brito, J., Castillo, A.: Bitcoin: A Primer for Policymakers. Policy 29, 3-12 (2014)

11. Grinberg, R.: Bitcoin: An Innovative Alternative Digital Currency. Hastings Science \& Technology Law Journal 4, 160-208 (2011)

12. Glaser, F., Zimmermann, K., Haferkorn, M., Weber, M.C., Siering, M.: Bitcoin Asset or Currency? Revealing Users' Hidden Intention. In: European Conference on Information Systems 2014, pp. 1-14

13. Bohr, J., Bashir, M.: Who Uses Bitcoin? An exploration of the Bitcoin community. In: Twelfth Annual International Conference on Privacy, Security and Trust (PST), pp. 94-101 (2014)

14. vom Brocke, J., Simons, A., Niehaves, B., Riemer, K., Plattfaut, R., Cleven, A.: Reconstructing the giant: On the importance of rigour in documenting the literature search process. In: European Conference on Information Systems 2009, pp. 2206-2217

15. Levy, J., Ellis, T.J.: A Systems Approach to Conduct an Effective Literature Review in Support of Information Systems Research. Informing Science Journal 9, 181-212 (2006)

16. Webster, J., Watson, R.T.: Analyzing the past to prepare for the future: Writing a literature review. MIS Quarterly 26, 13-23 (2002)

17. Chen, H., Chiang, R.H.L., Storey, V.C.: Business intelligence and analytics: From big data to big impact. MIS Quarterly 36, 1165-1188 (2012)

18. Nakamoto, S.: Bitcoin: A Peer-to-Peer Electronic Cash System (2008)

19. Scott, B.: Peer-to-Peer Review: The State of Academic Bitcoin Research 2014, http://suitpossum.blogspot.de/2014/12/academic-bitcoin-research.html

20. Böhme, R., Christin, N., Edelman, B., Moore, T.: Bitcoin: Economics, Technology, and Governance. Journal of Economic Perspectives 29, 213-238 (2015) 
21. Verbücheln, S.: How Perfect Offline Wallets Can Still Leak Bitcoin Private Keys (2015)

22. Andrychowicz, M., Dziembowski, S., Malinowski, D., Mazurek, L.: Secure Multiparty Computations on Bitcoin. In: 2014 IEEE Symposium on Security and Privacy (SP), pp. 443-458 (2014)

23. Babaioff, M., Dobzinski, S., Oren, S., Zohar, A.: On bitcoin and red balloons. In: Faltings, B., Leyton-Brown, K., Ipeirotis, P. (eds.) EC '12 Proceedings of the 13th ACM Conference on Electronic Commerce, pp. 56-73 (2012)

24. Feld, S., Schönfeld, M., Werner, M.: Traversing Bitcoin's P2P network: insights into the structure of a decentralised currency. International Journal of Computational Science and Engineering (forthcoming)

25. Biryukov, A., Khovratovich, D., Pustogarov, I.: Deanonymisation of clients in Bitcoin P2P network. CoRR abs/1405.7418 (2014)

26. Decker, C., Wattenhofer, R.: Information propagation in the Bitcoin network. In: 2013 IEEE Thirteenth International Conference on Peer-to-Peer Computing (P2P), pp. 1-10 (2013)

27. Baek, C., Elbeck, M.A.: Bitcoins as an investment or speculative vehicle? A first look. Applied Economics Letters 22, 30-34 (2015)

28. Wu, C.Y., Pandey, V.K.: The Value of Bitcoin in Enhancing the Efficiency of an Investor's Portfolio. Journal of Financial Planning 27, 44-52 (2014)

29. Ali, R., Barrdear, J., Clews, R., Southgate, J.: Innovations in payment technologies and the emergence of digital currencies. Bank of England Quarterly Bulletin 54, 262-275 (2014)

30. Kristoufek, L.: BitCoin meets Google Trends and Wikipedia: quantifying the relationship between phenomena of the Internet era. Scientific Reports 3, 1-7 (2013)

31. Kondor, D., Csabai, I., Szüle, J., Pósfai, M., Vattay, G.: Inferring the interplay between network structure and market effects in Bitcoin. New Journal of Physics 16, 1-10 (2014)

32. Raiborn, C., Sivitanides, M.: Accounting Issues Related to Bitcoins. Journal of Corporate Accounting \& Finance 26, 25-34 (2015)

33. van Alstyne, M.: Why Bitcoin Has Value. Communications of the ACM 57, 3032 (2014)

34. Holmquist, E.: Bitcoin and the Coming Revolution in Financial Transactions. RMA Journal 97, 23-29 (2014)

35. Angel, J.J., McCabe, D.: The Ethics of Payments: Paper, Plastic, or Bitcoin? Journal of Business Ethics, 1-9 (2014)

36. Zarifis, A., Efthymiou, L., Cheng, X., Demetriou, S.: Consumer Trust in Digital Currency Enabled Transactions. In: Abramowicz, W., Kokkinaki, A. (eds.) Business Information Systems Workshops, 183, pp. 241-254. Springer International Publishing, Cham (2014)

37. Lin, P., Chung, P.-C., Fang, Y.: P2P-iSN: a peer-to-peer architecture for heterogeneous social networks. IEEE Network 28, 56-64 (2014)

38. Maurer, B., Nelms, T.C., Swartz, L.: "When perhaps the real problem is money itself!": the practical materiality of Bitcoin. Social Semiotics 23, 261-277 (2013) 
39. Ahamad, S.S., Nair, M., Varghese, B.: A Survey on Crypto Currencies. In: 4th International Conference on Advances in Computer Science, AETACS, pp. 42 48 (2013)

40. Ametrano, F.M.: Hayek Money: The Cryptocurrency Price Stability Solution. SSRN Journal August 19, 2014, 1-54 (2014)

41. Wiatr, M.: Bitcoin as a Modern Financial Instrument (2014)

42. Spenkelink, H.: The adoption process of cryptocurrencies. Identifying factors that influence the adoption of cryptocurrencies from a multiple stakeholder perspective (2014)

43. Vigna, P., Casey, M.J.: The age of cryptocurrency. How Bitcoin and digital money are challenging the global economic order. St. Martin's Press, New York, NY (2015)

44. Dinu, A.: The Scarcity of Money: The Case of Cryptocurrencies. Master' Thesis (2014)

45. Papp, J.: A Medium of Exchange for an Internet Age: How to Regulate Bitcoin for the Growth of E-Commerce. Pittsburgh Journal of Technology Law and Policy 15, 33-56 (2014)

46. Bayern, S.: Dynamic Common Law and Technological Change: The Classification of Bitcoin. Washington and Lee Law Review Online 71, 22-34 (2014)

47. Citi GPS: Disruptive Innovations II - Ten More Things to Stop and Think About (2014)

48. Andersson, G., Wegdell, A.: Prospects of Bitcoin. An evaluation of its future (2014)

49. Antonopoulos, A.M.: Mastering Bitcoin: Unlocking Digital Cryptocurrencies. O'Reilly \& Associates, Sebastopol, CA (2015)

50. Descôteaux, D.: Bitcoin: More Than a Currency, Potential for Innovation. (2014)

51. Dostov, V., Shust, P.: Cryptocurrencies: an unconventional challenge to the AML/CFT regulators? Journal of Financial Crime 21, 249-263 (2014)

52. Evans-Pughe, C., Novikov, A., Vitaliev, V.: To Bit or Not to Bit? Engineering \& Technology 9, 82-85 (2014)

53. Stokes, R.: Virtual money laundering: the case of Bitcoin and the Linden dollar. Information \& Communications Technology Law 21, 221-236 (2012)

54. Bryans, D.: Bitcoin and Money Laundering: Mining for an Effective Solution. Indiana Law Journal 89, 441-472 (2014)

55. Brezo, F., Bringas, P.G.: Issues and Risks Associated with Cryptocurrencies Such as Bitcoin. In: Berntzen, L., Dini, P. (eds.) SOTICS 2012. The second international conference on social eco-informatics, October 21-26, Venice, Italy, pp. 20 26. IARIA (2012)

56. Trautman, L.J.: Virtual Currencies: Bitcoin \& What Now after Liberty Reserve and Silk Road? Richmond Journal of Law and Technology 20 (2014)

57. Pagliery, J.: Bitcoin and the future of money. Triumph Books, Chicago, IL (2014)

58. Krugman, P.R.: Bitcoin is evil. New York Times 2012 (2013)

59. Cheung, A., Roca, E., Su, J.-J.: Crypto-currency bubbles: an application of the Phillips-Shi-Yu (2013) methodology on Mt. Gox bitcoin prices. Applied Economics 47, 2348-2358 (2015) 
60. Ghauri, P.N., Grønhaug, K.: Research methods in business studies. A practical guide. Financial Times Prentice Hall, Harlow, England, New York (2005)

61. Creswell, J.W., Plano Clark, V.L.: Designing and conducting mixed methods research. Sage, Thousand Oaks, CA (2007)

62. Denzin, N.K., Lincoln, Y.S.: The Sage Handbook of Qualitative Research. Sage, Thousand Oaks, CA (2011)

63. Hair, J.F., Wolfinbarger, M., Money, A.H., Samouel, P., Page, M.J.: Essentials of Business Research Methods. M.E. Sharpe, Armonk, NY (2011)

64. Miles, M.B., Huberman, A.M.: Qualitative Data Analysis. Sage, Thousand Oaks, CA (1994)

65. Eisenhardt, K.M.: Building Theories from Case Study Research. Academy of Management Review 14, 532-550 (1989)

66. Kvale, S., Brinkmann, S.: InterViews. Learning the craft of qualitative research interviewing. Sage, Thousand Oaks, CA (2015)

67. Strauss, A., Corbin, J.: Grounded Theory: Grundlagen qualitativer Sozialforschung (Basics of Qualitative Research). Beltz, Weinheim, Germany (1996)

68. Miles, M.B., Huberman, A. Michael: Drawing Valid Meaning from Qualitative Data: Toward a Shared Craft. Educational Researcher 13, 20-30 (1984)

69. Hesse-Biber, S.N., Leavy, P.: The Practice of Qualitative Research. Sage, Thousand Oaks, CA (2006)

70. Flick, U.: Managing quality in qualitative research. Sage, London, UK (2008)

71. Shenton, A.K.: Strategies for ensuring trustworthiness in qualitative research projects. Education for Information 22, 63-75 (2004)

72. Davis, F.D.: Perceived Usefulness, Perceived Ease of Use, and User Acceptance of Information Technology. MIS Quarterly 13, 319-340 (1989)

73. Davis, F.D., Bagozzi, R.P., Warshaw, P.R.: User Acceptance of Computer Technology: A Comparison of two Theoretical Models. Management Science 35, $982-$ 1003 (1989)

74. Venkatesh, V.: Determinants of Perceived Ease of Use: Integrating Control, Intrinsic Motivation, and Emotion into the Technology Acceptance Model. Information Systems Research 11, 342 (2000)

75. Venkatesh, V., Davis, F.D.: A Theoretical Extension of the Technology Acceptance Model: Four Longitudinal Field Studies. Management Science 46, 186 (2000)

76. Silverman, D.: Doing qualitative research (2013)

77. Garcia, D., Tessone, C.J., Mavrodiev, P., Perony, N.: The digital traces of bubbles: feedback cycles between socio-economic signals in the Bitcoin economy. Journal of the Royal Society Interface 11, 1-28 (2014)

78. Kostakis, V., Giotitsas, C.: The (A)Political Economy of Bitcoin. TripleC 12, 431-440 (2014)

79. Papilloud, C., Haesler, A.: Distinktion: The veil of economy: electronic money and the pyramidal structure of societies. Scandinavian Journal of Social Theory $15,54-68$ (2014) 